Article

\title{
Policies for a More Dematerialized EU Economy. Theoretical Underpinnings, Political Context and Expected Feasibility
}

\author{
Andrea Bigano ${ }^{1,2, *}$, Aleksander Śniegocki ${ }^{3}$ and Jacopo Zotti ${ }^{1,4}$ \\ 1 Fondazione Eni Enrico Mattei (FEEM), Milano 20123, Italy; jacopo.zotti@deams.units.it \\ 2 Euro-Mediterranean Center on Climate Change (CMCC), Lecce 73100, Italy \\ 3 Warszawski Instytut Studiów Ekonomicznych (WISE), Warszawa 02-001, Poland; \\ aleksander.sniegocki@wise-europa.eu \\ 4 Department of Political and Social Sciences, University of Trieste, Trieste 34127, Italy \\ * Correspondence: andrea.bigano@feem.it; Tel.: +39-025-203-6934
}

Academic Editor: Vincenzo Torretta

Received: 9 February 2016; Accepted: 12 July 2016; Published: 28 July 2016

\begin{abstract}
Economic systems are connected to the natural environment through a continuous flow of energy and materials. The production of economic wealth implies the use of natural resources and their transformation into goods (bound to become, at least partially, waste in the future), current waste (pollution) and low-valued energy (entropy). The scarcity of natural resources and the negative externalities arising from their use throughout the entire value chain are quite natural motivations for the current policy push towards a more dematerialized and a more circular economy. In this perspective, the EU seems to be approaching a new frontier in environmental policy. The main contribution of this paper is a qualitative assessment of a coordinated set of dematerialization policies, which aim at fostering the socially efficient use (and re-use) of virgin materials at firm level. The policy mix we propose envisages a green tax reform (GTR) with a material tax, which aims at shifting relative input prices in favour of labour and capital, and a policy of funding research and development activities in the area of resource efficiency. In order to support firms in their transition to higher material efficiency, we foresee targeted skill enhancement programmes. Finally, to prevent firms to shift towards less material-intensive production, potentially leading to lower output quality, we complete the policy mix with specific command-and-control measures, aiming at setting minimum quality standards for selected product categories. The qualitative assessment of this mix of policies relies on the four basic criteria of the economic policy analysis (effectiveness, efficiency, equity and feasibility). Since the EU is deeply integrated in the world economy, and it is a net importer of virgin resources, our policy evaluation necessarily takes an open-economy perspective. In this vein, the paper reviews the state of affairs of the major world countries (USA, Japan and China in particular) on this issue, and contextualizes the EU action in a global perspective.
\end{abstract}

Keywords: dematerialization; absolute decoupling; resource efficiency; policy mixes; qualitative assessment

JEL Classification: H23; O44; Q01; Q32

\section{Introduction}

In recent years, global consumption of natural resources has drastically increased [1]. In terms of growth rates, in the decade between 2003 and 2013, these have more than doubled the values of the preceding twenty years, and in some cases, they reached unprecedented levels in the range of five percent per year [2]. This evolution, which is mostly due to the acceleration in the growth 
process in emerging countries (e.g., China and India), raises two major concerns. One relates to the resource limitedness problem (i.e., the fact that the stock of resources on Earth is finite and even if some resources naturally regenerate, all resource stocks may be exhausted if not properly managed). The other comes from the simple intuition that larger extracted quantities inevitably mean larger externalities. Negative environmental impacts arise in connection with extraction and refinement activities as well as with the transformation of raw materials into finished products. Once the latter reach the end of their economic life, they eventually become waste, which is usually a further source of externalities.

There are contrasting views in the academic debate about the seriousness of this type of issue. Some authors [3-6] are convinced that they are substantially irrelevant, while others [7,8] believe that a different growth paradigm is simply needed in order to better combine income growth and environmental preservation. This paradigm is currently known as green growth or sustainable growth [7]. According to [8], green growth refers to the possibility of "preserving or enhancing aggregate natural capital within a specific area, or possibly the planet as a whole" while maintaining positive income growth. This definition assumes that the adverse environmental impacts of the economy (broadly referred to below as "pollution" and including also resource consumption) do not exceed the natural self-regeneration capability of the environment. If pollution (as a flow variable) is above this level, it has to decrease. An alternative, more restrictive definition (proposed by Robert Ayres), understands green growth as the solution to the "problem of maintaining economic growth, while reducing pollution and/or its impacts" [7]. Here, the reduction of the initial levels of pollution is considered a prerequisite whatever their relation with the regeneration capability of the environment. These two concepts of green growth are indeed special cases of a broader definition, which accounts for both the case in which pollution has to decrease and the case in which pollution may remain constant.

The construct of green growth may be easily rephrased in terms of virgin resource consumption. Consider the basic fact, originally observed by [9], that the economy is an open system (in a thermodynamic sense), which is embedded in the larger natural environment. The economy takes energy and matter (i.e., virgin resources) from the natural environment and transforms them into (low-valued) energy and other matter, which eventually goes back to the environment in the form of (solid, liquid and air) pollution. Consumption goods, in fact are in any case destined to become waste, i.e., pollution. The fact that the economy barely transforms virgin resources in pollution allows the identification of green growth with the possibility of maintaining positive income growth with constant or falling consumption of virgin resources. When resource consumption remains constant or falls and economic growth is positive, the level of resource efficiency in the economy rises (This is indeed the concept used by the EU [10] in its "Roadmap to a Resource Efficient Europe", which was preceded by the 2005 "Thematic Strategy on the Sustainable Use of Natural Resources" [11]). Higher resource efficiency obviously means lower resource intensity according to the macroeconomic relationship that linearly links GDP to resource use. In this perspective, green growth means de-intensification or, more appropriately, dematerialization [12]. In formal terms, dematerialization occurs when the growth rate of resource consumption is lower than the GDP growth rate. If resource consumption is constant or decreasing and income growth is positive, we observe green growth. In 2002 the OECD started to label this development with the term absolute decoupling (being relative decoupling the case of positive resource consumption growth at a lower rate than GDP growth).

This paper understands green growth as absolute decoupling, as it assumes the need for decreasing resource consumption while maintaining positive income growth. It discusses a selected mix of policies in order to assess their capability to foster absolute decoupling of the EU economy from the use of virgin materials (i.e., wood, metals and non-metallic minerals). To this aim, it further specifies the concept of environment that is used in the definition of green growth. It acknowledges that it is not a uniform aggregate but it is composed by several parts (air, land, soil, subsoil, water, biodiversity, biosphere, ozone layer ...) which provide different goods and services to the economy. In this perspective, it differs from that strain of literature, which assumes a highly stylized world and in this context derives formal conditions for green growth to occur. Prominent examples of this literature 
are contributions by Smulders [13,14] who extend the standard Lucas [15] endogenous growth model to include the environment, and conclude that green growth (in the sense of [8]) is theoretically possible when sufficient knowledge is accumulated, in order to counterbalance the diminishing marginal returns of the natural environment. Other authors [16,17] insert the environment into the economic system from a more physical (i.e., thermodynamic) perspective, following an approach which is "consistent with the ideas of Georgescu-Roegen [18] and Daly [19]" [17]. They conclude that green growth (intended as in [7], see above) is feasible only up to an income growth rate, which lies in the range between $1.5 \%$ and $2 \%$. Above this limit, environmental Kuznets curves conjecture a bell-shaped relationship between environmental quality and per capita income in a country. Their empirical validity is generally regarded as questionable [20], "the environmental Kuznets curve is no longer observed" [16], and pollution continues to grow with economic activity. Moreover, they find that green growth may be achieved through general innovation together with specific innovation in the product mix, in presence of recycling and a functioning circular economy. While these results are underpinned by robust theoretical assumptions, they rest on models with only one sector, in which the environment is a single unspecified aggregate, and the economy is closed. Thus, their conclusions remain rather abstract and their policy relevance is limited.

The need for more concrete policy advice motivates a second type of literature, which trades off the robustness of general conclusions about green growth with more empirical considerations about its effective implementation in the real world. This paper belongs to this second type of literature, which is concerned with the concrete feasibility of dematerialization in the economy. Because of its focus on wood, metals and non-metallic minerals, it does not consider the links between the economy and the remaining types of resources, namely fossil energy materials (and carriers) and biomass other than wood. This type of approach is a common feature of this second strain of literature, which indeed complements the one mentioned in the previous paragraph. In the case of [21], for example, the authors study how the flows of zinc and lead into the Dutch economy react to a series of policies aiming at reducing their use. While the initiative may be successful in lowering the intensity of use of these two metals, the analysis is unable to provide results about other materials. This does not allow ruling out leakages from the sectors involved in the policy and other sectors in the economy. This issue arises in the case of a recent study by the EU Commission [22], which shows that absolute-decoupling policies, although beneficial for growth, may lead to higher $\mathrm{CO}_{2}$ emissions, as a consequence of missing absolute decoupling with regard to other types of natural resources. Another issue, which typically arises in this second type of literature, follows from the assumptions regarding the number of sectors in the economy. In the multi-sectoral case, a GDP drop in one sector due to a certain dematerialization policy needs to be contrasted with the aggregate GDP effect on the entire economy. This is important in [21]: The results entail negative GDP effects on the sectors where the use of the two metals is the most intensive.

In the area of the dematerialization policies focusing on virgin materials (i.e., wood, metals and non-metallic minerals), this paper concentrates on policies fostering the socially efficient use (and re-use) of materials at firm level. It is based on the research activity performed in the framework of the DYNAMIX project, which proposes a series of policies aiming at decoupling economic growth in the EU from natural resource consumption. The DYNAMIX project focuses on selected aspects of the environment, which are air, land, soil, biodiversity, subsoil as a provider of metals and non-metallic minerals. It designs three distinct policy mixes to promote absolute decoupling. Two of them focus respectively on materials and land (soil) while the third has an overarching character. The DYNAMIX project assesses the three policy mixes and the policies making up each policy mix from the environmental, economic, social and legal points of view, and both from a quantitative and a qualitative perspective. The qualitative aspects of the economic assessment are the subject of this paper. In this perspective, the present paper is complementary to the literature, which studies the opportunities offered by a shift in consumption habits. This involves for example a change in the consumption patterns towards the so-called "knowledge-products-computer software, new media, electronic databases and libraries, and Internet delivery of goods and services" [23] —which have the 
major feature of contributing to income growth without requiring intense virgin materials consumption, which characterizes standard consumption. This is the idea of the "weightless economy" [24], which can be found in [13] as well as in Hepburn and Bowen [25], who "observe (that) GDP is not synonymous with material output" [8]. Another promising research area is developing around the idea of circular economy. This term (already used in [26] and [7] with the wording "dematerialization") indicates those policies aiming at increasing recycling and reuse, in order to raise the percentage of non-virgin materials in the production process.

This paper extends the literature on dematerialization (e.g., [21,22]) in two directions. On one hand, it performs a qualitative policy analysis. To this aim, it gauges a selected mix of policies pursuing absolute decoupling against the four basic criteria of the economic policy analysis (effectiveness, efficiency, equity and feasibility). The core of the mix is given by a green tax reform, which includes a material tax, with the aim of shifting the relative production factor prices in favour of labour and capital, and a policy of funding research and development activities in the area of resource efficiency. Considering the costs that productive sectors could incur as a consequence of this policy, we complement it with information policies such as a measure aiming at offering targeted skill enhancement programmes in order to support firms in their transition towards more resource-saving production processes. Since firms are usually regarded as cost-minimizers, and this does not necessarily completely overlap with resource efficiency, a material tax may reach its goal of dematerializing the production process but may have a negative side effect, namely a less material-intensive and thus less durable production. To prevent this, we complement the policy mix with some command-and-control measures aiming at setting minimum quality standards for certain product categories.

On the other hand, the policy evaluation in this paper takes an open-economy perspective. In our belief, this is necessary for two reasons. First, the EU is deeply integrated in the world economy. Capital, as a production factor is highly mobile, and this deserves serious consideration in policy evaluation. Turner et al. [27] are among the first to highlight that firms may decide to migrate when conditions change (on this point, see for example [28,29]). Second, the EU is a net importer of virgin materials, which enter the economy either in the form of raw materials or after transformation in intermediates. The externalities connected with their extraction and their industrial processing arise in the exporting countries. In the case of the policy mix depicted above, this means that green growth entails maintaining growth in the EU while reducing environmental impacts also abroad. For policy acceptability in the EU, this is a crucial point. A second issue relates to the risk that the policy mix above may fail to reduce the externalities in the exporting countries. This question equally applies to the problem of natural resource limitedness, and it reflects the unilateral nature of the policy mix under scrutiny. Recent developments in global material flows support the notion that accounting for trade effects is crucial for assessing the actual progress towards absolute decoupling. As developed economies shift towards services, and resource-intensive production activities are relocated beyond their borders, the "hidden" flows of materials, which are embedded in trade increase [30]. In order to gauge this risk, the policy evaluation in this paper considers two factors: the global flows of virgin materials, which help contrasting the role of the EU with the other major world economies, and the political orientation of these countries towards the urgency of reducing natural resource consumption. Together, these elements allow a more comprehensive assessment of the effectiveness of the policy initiative, as well as of its acceptability.

Our assessment of the policy mix described above yields four main results. First, a comprehensive policy mix is far more promising than a single policy instrument, when the desired change in the economy is as profound as the one required by a dematerialization process. This is indeed consistent with the basic prescriptions of economic policy theory (see, for example, [31]) in the environmental area, in the presence of multiple externalities coming from multiple market failures at the same time (see, however, [32] for a summary of economic critiques regarding the overlapping of climate policy instruments.). Second, a policy mix such as the one proposed in this paper, needs a dynamic perspective for its complete deployment, in view of the substantial shift it imposes on the economy. 
Every individual component of the policy mix needs to be adopted according to a well-defined time sequence, which must take due account of the specific situation at the time of implementation. From this perspective, it is important to distinguish between policies with a typical support role (like, for example, skill enhancement programs) and those at the core of the whole policy intervention such as market-based measures. A dynamic approach to policy mix design is also desirable for a better distribution over time of the efforts required from the targeted agents in order to increase acceptability. Third, the analysis indicates that the policy mix under scrutiny may be indeed successful in setting the EU economy on a path of absolute decoupling, although the opportunities offered by offshoring or outsourcing material-intensive productions may undermine the effectiveness of the whole mix in a global perspective. This result is in line with the quantitative analysis contained in [22] and it is partly due to the double nature of the proposed policy mix, which entails binding measures on one side (i.e., a materials tax or enhanced product standards) and supporting instruments (i.e., funding policies of research and innovation activities in the area of resource efficiency and skill enhancement programmes) on the other. Last, we find that while the possible success of this policy mix in achieving absolute decoupling in the EU is invaluable, it may be unfortunately insufficient to reverse the current trend in worldwide resource consumption. This is due to various factors and in particular to the high-dependency of the EU economy on external (i.e., extra-EU) resource stocks and to the relatively small share of the EU economy in global resource consumption.

The rest of the paper is organized as follows. Section 2 provides some basic information regarding natural resource flows in the world and in the EU. Moreover, it briefly sketches the policy approach of other major world economies towards resource consumption. Section 3 illustrates the methods. Section 4 illustrates the main features of the policy mix to be assessed in this paper and Section 5 provides the results of this evaluation. Section 6 concludes.

\section{The Global Context}

The final objective of any dematerialization policy is a reduction of the extracted quantities. In the hypothetical case of a closed economy, this follows automatically from a reduction in resource consumption. In an open-economy framework, however the identity between extraction and consumption stops holding. Domestically extracted resources can be exported, and internal resource consumption relies upon imports from abroad. Because of the open-economy nature of the EU, our policy evaluation (Section 4) cannot neglect these issues. Since the policy mix assessed in this paper targets resource use in the EU, this section first discusses some data regarding consumption of virgin resources in the EU and in other major world economies. In the second part, it presents some basic information about political initiatives in the area of virgin materials in China, US and Japan. This discussion aims at providing the policy analysis with further elements, which can help better circumstantiate the effectiveness and the feasibility analysis in Section 4.

To measure resource consumption, this paper follows the approach of DYNAMIX that adopts the Raw Material Consumption (RMC) indicator. Note that RMC figures cannot be observed, and they need to be computed instead, using additional data (e.g., input-output matrices) and making specific assumptions; therefore, their levels differ from method to method. In [33], the authors compare various studies and show that the gap between results may be very high. In the case of the EU, comparable studies (e.g., [33,34]) fortunately deliver quite homogeneous results. This does not hold, however for the US, for which results in terms of RMC figures vary by more than $40 \%$ between [33] and [35].

The heterogeneity in computed RMC levels across studies needs serious consideration in any discussion based on RMC figures. This issue however, is even more crucial when it comes to policy intervention. In this perspective, in fact the whole policy strategy in this area may be undermined by an intrinsic uncertainty. Consider for example the fact that the US and the EU are among the world largest resource consumers. Uncertainty about their respective RMC levels is a politically relevant issue per se, because it eventually cast doubts about the responsibility towards the world for their consumption levels. In more general terms this issue deserves due attention in the assessment of the feasibility. 
One important factor influencing RMC results is the number of countries, which are considered exogenous in the computation exercise, and for which the domestic technology assumption is adopted. Clearly, computations involving larger number of countries are preferable, with other things being equal. Similarly, studies employing multiregional input-output (MRIO) matrices should be generally preferred to those based on single-region input-output (SRIO) matrices. In our knowledge, studies of the first type are [33-36]. In this section, we rely on this last computation as in our knowledge it is the one with the highest country-coverage.

Table 1 reports selected RMC figures from [33]. This data shows that the EU is the world second-largest consumer of metals and non-metallic minerals, with a share of around $17 \%$. RMC figures indicate the role that each country can play in terms of reduction of current consumption at the global level. Any country can ideally control its level of RMC, but the effects of a change in that level on total world extraction needs to be quantified through appropriate modelling instruments. Unfortunately, we are not aware of any study quantifying the effects on world RMC of a unilateral change in the RMC by the EU. This lack of knowledge is a crucial point in policy perspective, as it impairs a transparent communication of any measure aiming at reducing current RMC levels.

Table 1. Raw Material Consumption (RMC) data for the five world-largest resource consumers in 2008 (in megatonnes). Source: own calculations on [33].

\begin{tabular}{ccccccc}
\hline & $\begin{array}{c}\text { Construction Materials } \\
\text { (1) }\end{array}$ & \multicolumn{2}{c}{$\begin{array}{c}\text { Metal Ores } \\
\text { (2) }\end{array}$} & \multicolumn{2}{c}{$\begin{array}{c}\text { Total } \\
\text { (1) + (2) }\end{array}$} \\
\hline China & 9661.9 & $32.66 \%$ & 1449.4 & $20.76 \%$ & $11,111.2$ & $30.39 \%$ \\
EU-28 & 4974.5 & $16.81 \%$ & 1195.4 & $17.12 \%$ & 6169.9 & $16.87 \%$ \\
USA & 2849.9 & $9.63 \%$ & 950.7 & $13.61 \%$ & 3800.6 & $10.39 \%$ \\
India & 1627.6 & $5.50 \%$ & 150.3 & $2.15 \%$ & 1777.9 & $4.86 \%$ \\
Japan & 1435.7 & $4.85 \%$ & 373.7 & $5.35 \%$ & 1809.5 & $4.95 \%$ \\
World total & $29,584.8$ & & 6982.9 & & $36,567.7$ & \\
\hline
\end{tabular}

Basic economic theory suggests that a given reduction in resource demand (due to lower consumption by one country) results in an equilibrium demand change, which is lower than the original demand change, unless global resource supply is infinitely elastic. In a "conservative" scenario, in which foreign economic actors maintain their behaviour unchanged, this implies that the extracted quantities at world level fall by less than the original demand reduction. Under this assumption, the national consumption shares in Table 1 can be interpreted as upper bounds of the elasticities of world RMC with respect to national RMC levels. In this perspective, a reduction in the EU resource consumption by an ambitious $50 \%$ would cause a drop in global RMC by less than $7.83 \%$. If the RMC in metal ores were to decline by $80 \%$ (as indicated in one of the Project key targets) the effect would be no larger than $-13.69 \%$ for global metal ores RMC. These results are clearly very simplistic because they assume that foreign countries do not react to the lower demand for natural resources. Under this proviso, however they convey the message that significant variations in the EU RMC are destined to bring about quite contained effects on global RMC. On the other hand, several "less conservative" scenarios can be imagined. If, for example, the RMC reduction is the result of a series of technological improvements, it can be supposed that these rapidly transfer to other countries which adopt them and start reducing their RMC as well. However, this is not necessarily the case, as technology may be costly or the internal situation may hinder their adoption [37]. Moreover, Table 1 shows that more than $60 \%$ of total RMC is due to four countries plus the EU while all remaining countries consume a much lower share of resources. This suggests that the aggregate consumption levels of the five (or ten) largest resource consumers may be plausibly decisive in changing current global trends in resource consumption. Although the willingness of these countries to act together in this direction is obviously very hard to assess, we try to provide some insight in this respect in the next paragraphs.

In order to analyse the EU approach to dematerialization in a global context, we first provide an overview of the EU Action Plan for the Circular Economy, which was announced in December 2015. While a number of various dematerialization policies were implemented on the level of Member 
States, the Plan provides the first comprehensive framework in this area at the EU level. Next, we compare the approach presented in the Plan with policy actions in three major global economies: Japan, USA, and China.

In order to map the initiatives announced in the EU Action Plan for the Circular Economy, we apply the policy classification used in the DYNAMIX project [38]. The mapping approach summarised in Table 2 allows us to distinguish several important features of the current strategy for dematerialization in the EU. First, its scope is very broad and includes all the stages of product lifecycle. This is a notable change compared to the current legal framework, as well as previous Circular Economy Package proposal tabled in 2014 [39], which were both focused on waste management targets. Second, there are no absolute limits set for the consumption of materials. This lack of strong policy targets in the area of resource efficiency stands in sharp contrast with the EU approach to climate and environmental policy, where absolute emission caps are the foundation for policy action. Third, the policy mix proposed in the Plan does not include any overarching price mechanisms related to material use (e.g., cap and trade schemes or taxes on material use, the latter being more challenging to introduce due to the unanimity requirements, i.e., the fact that every Member State has to support the change in the EU taxation rules), which could provide the EU-wide price signal to move towards a more circular economy [40]. Instead, the Plan focuses mainly on regulatory, cooperation-, and information-based measures on the EU level, while encouraging the Member States to introduce tax measures on their own. These three features confirm previous findings on the EU resource efficiency policy, which suggested that the latter is framed mainly as an economic rather than environmental policy [41]. All in all, this results in a focus on relative rather than on absolute decoupling.

Table 2. Policy instruments included in the EU Action Plan for the Circular Economy classified according to DYNAMIX typology.

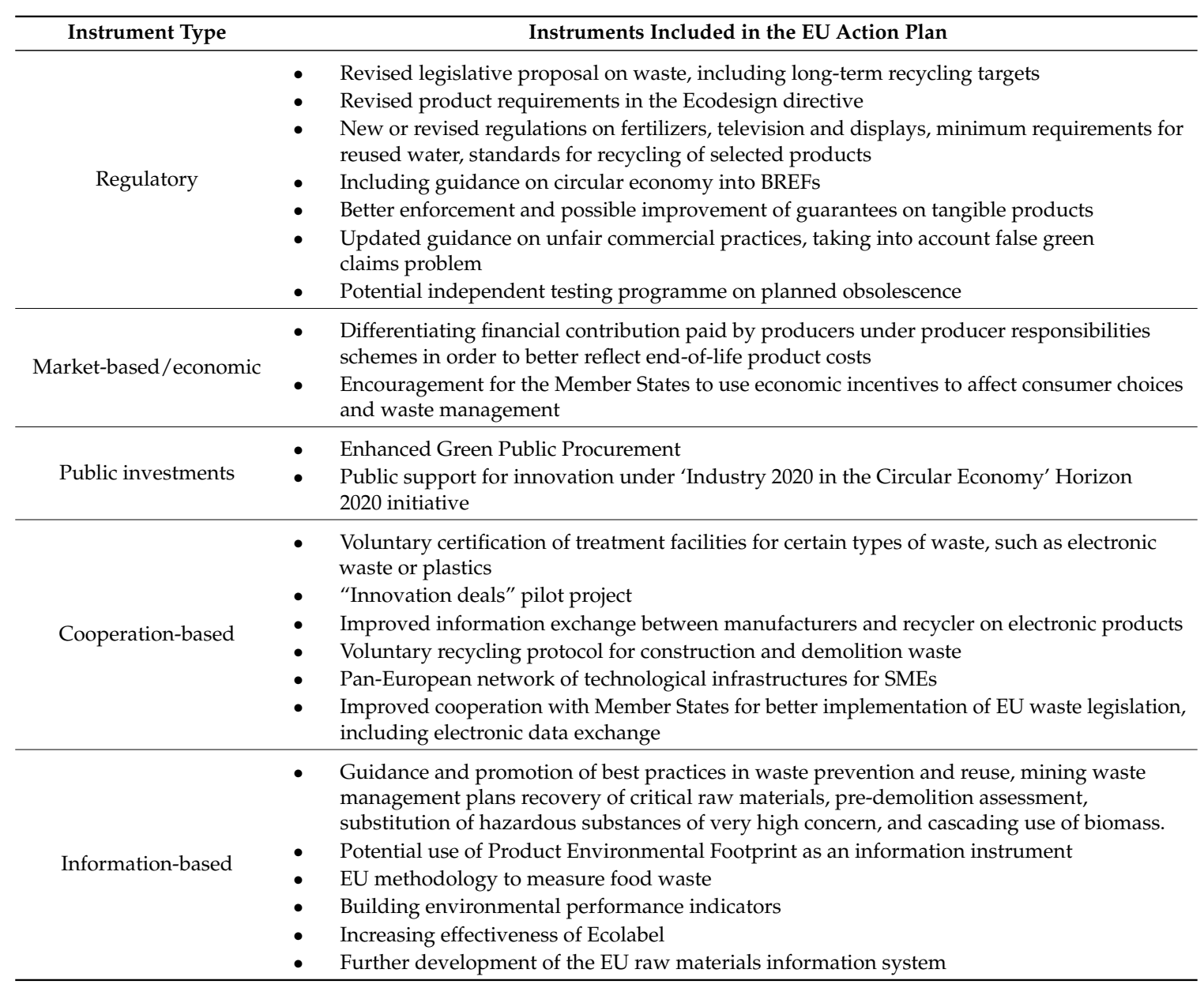


The move towards a more material efficient economy is not limited to the EU. Policy initiatives in this area have emerged in recent years in Japan, USA, and China. Japan is an early-mover, having adopted the Basic Act for Establishing Sound Material-Cycle Society in 2000, followed by two Fundamental Plans from 2003 and 2008. The Japanese policy involves a broad mix of measures covering the whole value chain, focused mainly on material efficiency improvement through both research and development (R\&D) support and product standards, as well as providing incentives and removing barriers to recycling [42]. Similar to the EU, most of the policy targets are relative rather than absolute, with a notable exception of waste reduction goal [43]. Focus on the material efficiency and recycling in Japan is motivated by high dependence on imported materials, like in the EU, while the framing and construction of the policy mix stems from local institutional, cultural, and economic specifics [42].

While there are policy initiatives focused on material efficiency in the United States, there is no federal framework or targets in this area [44]. Public intervention occurs mainly at the state level and focuses on recycling, while at the federal level EPA provides information and coordination campaigns promoting the idea of Sustainable Materials Management [45]. Thus, there is a significant difference in policy stringency between the United States and both the EU and Japan, which may be explained by more favourable resource endowment of the former.

China was one of the first countries to embrace the concept of Circular Economy in its legislation, by adopting the Circular Economy Promotion Law in 2009; policy targets related to more efficient resource use and reducing pollution were also included in the 11th and 12th Five-Year Plans [46]. While China is not as dependent on material imports as Japan or the EU, the top-down Circular Economy promotion may be seen as a way to balance environmental and social concerns with a rapid economic development [46], as well as address longer-term national security and competitiveness concerns [47]. While the national policy provides consistent framework for promoting material efficiency and recycling, implementation of the concrete actions on the local level remains challenging [46-48]. There are also no absolute targets for material use reductions [43].

Placing the EU approach to dematerialization in the global context allows three main conclusions to be drawn. First, the current Circular Economy package is-together with the Japanese Sound Material-Cycle Society initiative-at a global forefront of dematerialization policies, both in terms of scope and ambitions. Second, the EU and major global economies still have not introduced policy mixes aimed at achieving absolute decoupling of material use from economic development. Third, the current level of policy ambition is not likely to lead to significant dematerialization [41,43].

\section{Methods}

In this section, we briefly describe the methodological approach applied in our study. Due to its qualitative nature, it strongly relies on the findings of the existing economic policy literature. The policy evaluation exercises performed by this type of literature are usually guided by four criteria, effectiveness, efficiency, equity and feasibility [49]. Our assessment of both the single policy measures and of the policy mix as a whole is based on these criteria. Their application does not follow a standardized protocol as in the case of empirical or experimental studies. This does not exclude, however, that our evaluation exercise exhibits a clear systematic structure, which entails two main steps, summarized as follows. The first step is a thorough screening of the existing literature with the aid of scientific search engines (e.g., EBSCO ${ }^{\circledR}$, Google Scholar ${ }^{\circledR}$ and Scopus ${ }^{\circledR}$ ). For our exercise, both theoretical contributions (including review papers) and empirical studies are in principle relevant. Among the latter, we gave priority to those focusing on the EU and on its member States. As a rule, we considered papers published since 2000 and earlier seminal papers. The second step consists in analysing those findings, which help to shed light on the performance of the policy measures under investigation.

Clearly, we cannot be sure to have covered the universe of publications in the field of interest of this paper. However, we are quite confident to have covered the most relevant ones, among which 
we can count a number of comprehensive survey studies that add, indirectly to the completeness of our coverage of the relevant literature. Thus, we are reasonably confident about the robustness of our findings. Note that the qualitative approach adopted makes the robustness of our conclusion less dependent from specific values and statistical relationship, and thus more robust in general terms. In order to keep this analysis as systematic as possible, we adopted the four criteria mentioned above, which we briefly illustrate in the remaining section. The relative weights of these criteria mostly reflect the relevance placed upon them by the literature, which first looks at policy efficiency and effectiveness and less frequently to feasibility and equity.

Effectiveness is usually defined as the capability of a policy to achieve a given target (e.g., [50] in [51]) while efficiency contrasts the net benefits of reaching this target with the net costs of the policy implemented to reach it. Both effectiveness and efficiency are to a great extent measurable, and hence their qualitative assessment involves two types of evaluations. One is based on the results of existing quantitative studies; the other is based on a series of more qualitative considerations, which are motivated by the fact that both effectiveness and efficiency cannot be quantified in all their aspects, as this is usually too costly.

Equity has to do with the heterogeneity of impacts that a policy has on different groups within the same category. Policy analysis usually focuses on three categories of actors, namely households, firms and sectors. A policy may in fact worsen income distribution among different groups of families. At the firms' level, small enterprises and large companies may be differently able to cope with the same set of rules with important consequences on their profitability. Different sectors, in turn, may unevenly be affected in terms of competitiveness as a consequence of the same policy. A comprehensive policy evaluation clearly requires reconciling various perspectives. Moreover, when a policy has a supra-national dimension, its effects may be different across countries, and this calls for careful attention. In a wider perspective, if a policy is implemented in a relatively large economy like the EU, this may also bring about several impacts on third countries.

Feasibility has to do with the level of difficulty associated with the introduction and the implementation of a policy, even when the policy is in principle fair, effective and efficient. In the relevant literature (e.g., [52]), there is agreement that an effective and efficient policy may be indeed difficult to implement. Although important for feasibility, equity is not always decisive in this case. Effectiveness and efficiency are necessary but simply not sufficient for successful implementation (on this point, see also [53] in the area of energy policy). Feasibility is far less easy to quantify than the first three attributes, because it is mostly influenced by non-quantifiable factors, which have to do with institutional, social and even cultural aspects. In general, it strongly depends on the types of actors affected by the measure, by their ability to convey their own interests into the policy process and by the evolution of their interactions. Thus, it is quite difficult to predict how different groups will react to a specific policy proposal and how they will behave during the process leading to the final decision on it. Two types of studies can help in shedding light on this issue. On one hand, there are "studies of behavioural responses to environmental taxes" [51] such as those reporting the results of the PETRAS project on policy options in the energy area (Energy Policy [54]). On the other hand, there are studies analysing the process behind the introduction of a new policy and how this may be steered by various stakeholder groups (see for example [55] on the introduction of a fat tax in Denmark). Unfortunately, however, studies of both these types are very few and their strict connection with specific policy initiatives hampers in any case their generalization to other contexts.

\section{The Policy Mix}

This section describes the main features of the policy mix, which is the object of the qualitative assessment exercise in this paper. In order to illustrate the logic behind its structure, let us recall the standard sequence of economic activities, which starts with the extraction of virgin materials and ends with their final disposal. We group these activities into three phases. Phase 1 includes the extraction and refinement operations, which prepare materials for their "first industrial use" [56]. 
Phase 2 involves their transformation into final consumption products. Phase 3 involves consumption and final disposal. Since the policy mix aims at fostering the socially efficient use (and re-use) of materials at firm level, its sphere of intervention regards the "first industrial use" of materials. Its aim is twofold, and it reflects the principles of green growth. On one hand, it pursues the reduction of externalities related to the extraction and refinement activities. On the other hand, it eventually contributes to reduce virgin material use. It is important to note that the objective of the policy mix is not the internalization of the external costs of production, which arise in Phase 2. Once materials enter the manufacturing process (Phase 2), externalities clearly arise from their transformation, but the nature of these impacts is mostly sector-specific. From this viewpoint, a policy initiative targeting sectorial externalities is basically a sector-specific policy, which ideally complements the intervention of this policy mix.

In view of its specific focus, the policy mix in this paper differs from any of the three policy mixes designed in the DYNAMIX Project. That project, in fact has a broader focus on resources, covering land, soil and air while this paper is concerned with virgin materials (metals and non-metallic minerals) and wood only. The broader focus in the project mostly motivates the "Policy Mix for Land Use", which aims at reducing land use impacts, and some specific policies in the "Overarching Policy Mix". Moreover, the project features a wider initiative towards dematerialization, which directly targets the wider sphere of production (Phase 2), consumption and disposal activities (Phase 3) and generally promotes a more circular economy. This explains the scope for a set of specific measures included in the "Policy Mix for Metals and other Materials" and in the "Overarching Policy Mix". These are for example the "Circular Economy Tax Trio" and the green fiscal reform aiming at the "Internalisation of external environmental costs". The policies contained in the mix presented here partly belong to the "Overarching Policy Mix" and partly to the "Policy Mix for Metals and other Materials" of the DYNAMIX project. (For a thorough description of their features, the interested reader is referred to [57].)

Our characterisation of the policy mix follows a sort of bottom-up approach. First, it deals separately with the single policy instruments contained in the mix; then it provides a more comprehensive analysis of the policy mix as a whole. Consistently with the general aim of the policy mix, the core instrument is a material tax, which is raised on all virgin materials that enter the production process for their "first industrial use". The direct effect of this measure is a change in the relative price system faced by EU manufacturing firms. In order to avoid import substitution, the tax is imposed also on imports of refined materials (border tax adjustment). To improve both its effectiveness and its feasibility, this instrument is meant as a part of a green tax reform (GTR) scheme. This allows earmarking tax revenues to other policy instruments. Earmarking here is suggested only with a view to increase the feasibility of the measure. Note that in more general fiscal perspective, earmarking may decrease the overall efficiency of the allocation of public funds (see for instance $[58,59])$. This second instrument in the GTR is a policy of funding private research and development activities in the area of resource efficiency. We choose a subsidy (i.e., a market-based instrument) to induce innovation because of the general agreement in the relevant literature regarding the superiority of this type of measure in comparison to command-and-control instruments (This is a standard result in the area of technological adoption, which may not hold in some special cases-e.g., adoption of a specific technology for reasons connected to public safety or public health. In a Weitzman prices vs. quantities perspective [60], this would be a typical case of highly convex marginal benefit curve for which the risk of missing the right taxation level and hence inducing the wrong quantitative change is too high. However this line of reasoning mostly makes sense in a static perspective. In the perspective of inducing technological change, its applicability is less straightforward. In a dynamic perspective [61], point to the superiority of taxes or permits in inducing the firm to adopt innovation beyond the level prescribed of the standard, if the innovation gives a cost advantage and hence allows saving on taxes or on purchasing the allowances. This however remains ultimately an empirical matter, and more recent works in general cannot find an unambiguous ranking of policy instruments in view of promoting environmental $R \& D$.). In terms of inducing firms to perform $R \& D$, results are less clear 
cut, and, bar the seminal work by Magat [62], where command-and-control instruments are clearly out-performed by market-based ones, more recent works in general cannot find an unambiguous ranking of policy instruments in view of promoting environmental R\&D. Even within market-based instruments, Popp et al. [63] point to a fundamental undecidedness of the ranking on the basis of the available empirical evidence: the relative performance of policy tools appear to be ultimately depending on the circumstances. Command-and-control measures may particularly help to improve the effectiveness of the material tax in the short run, when the price elasticity of resource demand is typically low because of technology invariance. At the same time, the material tax may be beneficial for feasibility because a GTR generally conveys a signal of commitment by the government to the policy initiative [55]. Material tax revenues are not used for undefined budgetary operations but are earmarked to the policy goal [64].

The policy mix is completed by two additional measures. One of them (a skill enhancement programme) aims at further supporting firms on the path towards dematerialization. Firms face higher material prices, and they would find it convenient to modify their input mix from more resource-intensive to more labour-(or capital-)intensive combinations. However, this requires both technological improvement and skill enhancement at the same time. While the policy of funding private research and development activities in the area of resource efficiency aims at supporting firms in achieving the former goal, appropriate skill enhancement programmes ensure that labour forces are capable of effectively coping with firms' technological advances. The two policies described so far (i.e., the GTR and the skill enhancement programmes) allow highlighting the intrinsic dynamic nature of this policy mix. Both the policy fostering research activities and the skill enhancement programmes deploy their effects in the long run while the material tax is associated with much faster effects. Since the implementation and the unfolding of the effects of these measures have usually different time horizons-a tax can become operational in a few months depending on duration of the legislative process needed to make it effective, and can be applied una tantum or gradually over several years; the other two measures typically take a few to many years to yield significant results-timing in the deployment of the single instruments of the policy mix (sequencing) is a crucial condition for the effectiveness of the entire policy initiative.

The last instrument included in the policy mix is a set of product standards. The introduction of such type of measure may sound redundant in the presence of efficient environmental taxes. However, the rationale for adding this measure to the policy mix lies in the discrepancy between cost efficiency at firm level and material efficiency at aggregate level. A material tax might have the unfortunate drawback of inducing firms to simply save on materials to contain production costs. A mere reduction in material intensity, if neither compensated by higher use of primary factors (i.e., labour and capital) nor supported by technological changes, may translate into less durable products with the final effect of increasing waste flows. The product standards foreseen by this third policy instrument should help to contain this risk.

\section{Results}

This section illustrates the results of the qualitative assessment of the policy mix described in the previous section. The analysis follows the methodology illustrated in Section 3. In the first part, it discusses each policy instrument separately, while in the second part it reports on the outcome of the more general evaluation of the policy mix. For sake of exposition, the four criteria described in Section 4 will be treated separately throughout the whole section, although they are obviously interdependent.

\subsection{The Green Tax Reform (GTR)}

The quantitative literature on GTRs is quite extensive (see for example the surveys provided by Bosquet [28] and Gago et al. [53]) but the number of papers focusing on dematerialization policies is quite small, as this topic is quite novel in environmental policy. Two contributions worth mentioning are [21] and [22], which share the same finding that a GTR with a material tax can be effective in 
reducing material use. While this is alluring as a result, it calls for some caution, because both studies assume that capital cannot migrate, i.e., firms cannot relocate abroad. In current times of globalization, such an assumption seems difficult to support for an applied study, as it does not allow to consider one of the basic reactions firms might have towards costly policies. Of course, firms can outsource their material-intensive production tasks, since both models account for international trade. This option however seems potentially profitable only in [21] because the country coverage in [22], which includes the EU Member States and five other European countries, effectively limits the scope for firms to outsource. These differences in modelling international relations are a possible explanation for the moderate GDP drop, which comes with higher material efficiency in [21], while [22] finds that absolute decoupling is possible. Another reason may be that [22] allows for technological change while [21] assume that the sectorial material intensity remains unchanged. These two studies taken together thus suggest that the GTR designed in this paper may stand a good chance to prove effective in achieving absolute decoupling, if it is accompanied by adequate measures to cope with the risks arising from outsourcing. Moreover, they lend theoretical support to the view that a policy mix like the one assessed in this paper needs a dynamic perspective. In the short run, the policy may turn out to be quite ineffective because of the low elasticity of resource demand to price changes. In the long run, R\&D activities contribute to technological changes and materials' substitution possibilities in the production process improve.

Absolute decoupling however is not the final goal of the GTR under scrutiny, which aims at reducing the externalities arising from extraction and refinement activities. Unfortunately, the existing literature cannot help in assessing the possible effectiveness of the GTR under scrutiny regarding its environmental goals. Nor currently available data can, as shown in Section 2. If the RMC in the EU falls because of the introduction of such a policy measure, the level of domestic extraction (DE) does not necessarily follow. EU extracting firms may in fact react by boosting their exports in order to compensate domestic demand contraction. Similarly, at the global level, a reduction of EU material imports does not automatically translate into a lower DE, as showed in Section 2. Since the impact of a RMC reduction in the EU has unknown consequences on world $\mathrm{DE}$, the same holds regarding volumes to be disposed. Thus, these considerations highlight that absolute decoupling in one individual country or in a region such as the EU does not automatically yield a reduction in the externalities arising from material use.

Regarding the support policy to R\&D activities in the field of material efficiency, the theoretical economic literature is at best scarce, as in the case of GTRs. However, this is not really an obstacle for our assessment: we will simply apply some basic economic theory principles. Since Arrow [65], it is well known that in a free market, firms' investment in R\&D is below the socially desirable level. This provides an immediate justification for public support to $R \& D$ and it is per se a compelling argument supporting the effectiveness of policies fostering R\&D. In [63], in fact the authors argue that the introduction of policies aiming at containing environmental externalities does not imply higher $R \& D$ efforts by firms at all. Quite the contrary in fact, taxes on virgin materials or on final disposal may even discourage firms' efforts in R\&D, as shown by [66] in a game theoretical model of Cournot competition. The structure of the GTR under scrutiny which encompasses an environmental tax and an R\&D subsidy seems to find wide support in the literature. The literature quite unanimously deems that $R \& D$ policies are important, but it is their combination with other policies that yields the best results $[67,68]$. In general terms, environmental externalities need appropriate correction instruments while R\&D support measures help to improve the way this correction can be performed. In this perspective, policies that promote material efficiency such as a material tax should be a credible and steady feature for these markets, as they represent continuous incentives to innovate and have the potential to eventually bring innovations to reach the market and to be adopted by consumers.

Efficiency is usually a major strength of GTRs. This type of policy, in fact, usually pursues a correction of an environmental externality and brings about a reduction of another taxation measure, which has typically distortionary nature-only lump-sum taxes are not distortionary. In the specific 
case of the GTR under scrutiny, revenues from the environmental taxation are used to finance a subsidy fostering R\&D activities in resource efficiency, which are performed at a sub-optimal level before the implementation of the policy. While it is true that there are no reductions in any other distortionary tax, the GTR under scrutiny allows financing a subsidy without additional taxation, which would increase inefficiency (Baylor [69] provides a review of rankings of tax distortions in general equilibrium models and finds that in "neo-classical growth models (...) capital taxes are the most distortionary, followed by labour and then consumption taxes (while in endogenous growth models) results are more heterogeneous and vary across framework, settings, and ranking criteria."). From this perspective, the GTR under scrutiny appears to be an efficient instrument. However, a deeper analysis in view of its implementation in the real world reveals two main concerns. Regarding the material tax, recall that its goal is to contain the externalities from extraction and refinement activities. A first condition for its efficiency is that it takes in due account differences among material types. The extraction of different types of materials produces in fact different impacts (see Section 2). However, a uniform material-specific tax is still a very rough instrument. The same natural resource can be extracted and processed for its "first industrial use" using different technologies, which entail different external costs. The degree of environmental friendliness of available technologies may vary from case to case. Moreover, every unit of material employed in goods' production can be either disposed or re-used, and this means again different environmental impacts-both disposal and recycling activities generate externalities. Thus, the amount of externalities associated with one single unit of the same material can vary considerably, and taxing all units of the same material with the same rate turns out to be inefficient and counterproductive, as it also fails to incentivize both the adoption of greener technologies and the re-use of materials. The second concern is related to the R\&D subsidy, which clearly implies management costs. A relevant category of costs is associated with the procedures for the selection of projects and the deployment of funds. While it is true that these may follow already existing schemes, this does not exclude the possibility of inadequate or biased selection procedures that may jeopardise the overall efficiency of the measure. Clearly, an issue of asymmetric information arises. Proponents of research projects really know about their ability to perform the activities detailed in their proposals, the quality of their scientific staff and of the original methodologies they intend to deploy within the project much better than the funding institution, which has only indirect information on these aspects, mostly based on the reputation of the proponent. A major risk is that an invariant selection process induces learning effects in the applicants, without guaranteeing quality in the research activity to be performed. It is thus advisable to revise research proposal evaluation criteria periodically, and to envisage, if the amount of funds allows it, different funding programs, with different scope and selection criteria, in order to capture different profiles of research institutions and finance both fundamental and applied R\&D.

Equity is a well-known issue for most environmental taxes, and GTRs are no exception to this rule. Since they tax consumption throughout the whole value chain, and they lower other more distortionary (but progressive!) tax measures, a wide literature agrees on GTRs' regressive effects [53,70-72]. However, two main features differentiate the GTR under scrutiny from similar measures and help mitigating its regressivity. First, the suggested GTR targets the use of wood, metals and non-metallic minerals at firm level. One can thus expect that this measure does not affect too much the price level of the goods used to satisfy primary needs. The magnitude of the negative distributional effects also depends on which and how many of the goods are targeted by the tax. Second, the GTR under scrutiny does not include any tax reduction, which means that equity is threatened only once, i.e., by the environmental tax. Regarding the impacts of GTRs on sectorial competitiveness, the literature is not unanimous on this, with some studies [73-75] finding the effects on sectorial competitiveness to be negligible, while [28], in the context of energy policies, finds quite opposite empirical evidence. The negative effects on sectorial competitiveness in our case are probably higher than in more standard GTRs, which use revenues from the environmental taxation to abate firms' social contributions in the most affected sectors. This GTR structure would also foster policy effectiveness, as it lowers firms' 
convenience to relocate or outsource material-intensive productions abroad. Since it contains an R\&D subsidy, this GTR tends to affect differently firms within the same sector. While the material tax targets all firms in the same (proportional) way, we can expect that only a (limited) subset of firms will be eligible for R\&D funds. Although we all agree that from a positive point of view all firms should perform R\&D activities, theory suggests that this may not be the case in the real world. Above in this section we highlighted the risk of an invariant selection process with consequent learning effects in the applicants. Thus, we may expect that only few firms and in particular those with an established R\&D division will benefit from the subsidy while other (maybe smaller) firms will just face a competitiveness loss.

The feasibility of the GTR under scrutiny depends on which groups it mostly affects. Since it involves a material tax on firms' purchases of refined natural resources, targeted firms will be the first to oppose this GTR. They will promptly start intense lobbying activities-an extensive literature maintains that firms are the best organized to effectively convey their own interests (in the field of environmental policy, several authors conclude that lobbying activities can effectively influence the final choice of the environmental instruments [76-78] or they may affect the stringency of the policy (see [79] for a survey)). The case of the Danish fat tax, which was first introduced and then withdrawn [55] shows that firms tend to react very determinedly against unwanted policy proposals "by using tactics like filing lawsuits, supplying governments with industry-funded biased research". Thus, the government willing to implement the policy has to find support in other groups. These entail firms in other sectors, which may indeed benefit from the policy [21], and the general public. A part from some specific groups, which will quite probably support (e.g., environmentalists) or fiercely oppose the policy (e.g., workers in the most affected sectors), the general public can be thought of as a set of different actors, which unevenly perceive the role of the policy proposed by the government [80], and positions can be heterogeneous. The general public can be induced either to support or to oppose a given policy, and public support is an important determinant of feasibility [81-83]. If the policy is based on widely shared positions, this helps its implementation. Two interdependent aspects turn out to be crucial in this perspective: Communication and trust between the government and the general public. The public must be enabled to understand the reason and the objectives of the policy [84]. From a communication point of view, any policy needs to be clearly motivated by highlighting the issue to tackle and the chances for success. This is of course no easy task to perform for a government. In the specific case of GHG emissions, Dresner et al. [84] argue that "it is notoriously difficult to get the general public to care about ( . . ) invisible, abstract, large-scale and long-term problem(s)". In the case of the GTR under scrutiny things are at least equally difficult, since data on RMC are very heterogeneous and the effect of a change in the EU RMC on world RMC is basically unknown. These technical aspects will be promptly used by the opponents to this GTR to try to convince the general public about the ineffectiveness of such a measure.

Regarding trust, several considerations are in order. Unfortunately, there is a basic "distrust of the government and politicians in general, distrust of tax policies, and distrust of government intentions regarding ETR" [84]. The objectives of environmental taxation measures often risk to be mismatched with the much standard one of pure revenue collection [64]. The government needs to keep environmental objectives distinct from budget or broader economic goals [55]. To foster trust, government can send specific signals. An important one relates to the governmental body that is in charge of designing the policy. An environmental measure cannot be uniquely processed by committees dealing with fiscal or economic issues but appropriate environmental bodies must participate in the process. In a more long-term perspective the government cannot adjust an already introduced (environmental) tax according to budget needs and its design cannot pursue side-objectives like the minimization of administration costs for firms, as this may compromise its effectiveness and thus its acceptability. In the particular case of a GTR, the general public may even mistrust assurances that revenues are used as promised [84]. High transparency in their use becomes then a priority, which may be granted though the set-up of ad-hoc independent bodies with the task of monitoring 
that revenues are not diverted to other purposes. The coherence in governmental action is an important pillar of public trust. The proposed policy needs to be consistent with the general picture of the existing measures regarding materials. The existence of other measures, which may have a rationale in contrast with the one of the GTR, is clearly counterproductive. Consider, as an example, the case of Sweden in the metal production sector, which in 2010 was subsidized with $€ 40$ million while the metal recycling sector received only $€ 0.6$ million [85]. Another aspect related to feasibility and trust is coordination of GTRs within the EU. While recent evidence suggests that there is a renewed interest in GTR at the Member State level and some readiness to cooperate in this area, the preferred approaches to the reform differ significantly between the countries and any form of mandatory policy coordination seems to be unattainable [86]. This is also reflected in the EU Action Plan for the Circular Economy discussed in Chapter 2. Furthermore, if and when the common policy framework is developed, the EU Member States will have to agree on the level of ambition of the GTR. Analysis of current state of resource taxation in Europe [87] indicates that even if all Member States employ current best European practices in this area, it will still play a limited role in the European fiscal systems, with revenue amounting to less than $0.2 \%$ of GDP.

\subsection{Skill Enhancement Programmes}

A shift towards a more dematerialized and more circular economy requires specific green skills [88]. Both academic curricula and vocational training programmes should adjust to this new requirement. The challenges faced by many workers in an economy heading towards absolute decoupling would be different to those that they are currently facing. For instance, the development of clean energy sources requires new engineering skills. Therefore, the opening of new university faculties and vocational training programmes is needed to educate specialists in this area, who will be able to build, maintain and further enhance low-carbon energy infrastructure through R\&D efforts.

The main aim of skill enhancement programmes is to reduce the mismatch between skills that will be demanded in a more dematerialized and more circular economy and current qualifications of the workforce. Qualified academic staff should be able to conduct high quality research; enterprises will need professional staff and engineers that are familiar with the solutions which reduce material use as well as medium level staff trained at servicing new equipment. Therefore, the first challenge for Member States is to reform vocational schools and provide incentives for the universities to adjust their teaching programmes, in order to allow them to respond successfully to changing demand for skills on the labour market.

In order to successfully address the issue of mismatch between skills and education in the future labour market, policy makers need to know the exact nature of the mismatch. Therefore, research programmes targeting that problem are needed. The effectiveness of public skill enhancement programmes needs to be carefully examined. Private enterprises are the main source of both demand and funds to finance green skills [89], and as such, they should be actively involved in the development of skills enhancement programmes. The key role for the state in this area is providing coordination for the activities of other actors, as enterprises are in a better position to gauge which sort of skills are needed.

The skills enhancement programmes can potentially have important social impacts. Firstly, they reduce the frictional unemployment, shortening the period of unemployment after a lay-off. As it is usually stressful and difficult, skills enhancement programmes alleviate the negative social effects of labour market frictions. If they are effective, they can constitute significant support for standard labour market policies. Secondly, if skills enhancement programmes target low-income households in rural areas, they can contribute to poverty reduction through an increase in labour market participation. 


\subsection{Product Standards}

In general, the economic analysis of environmental policy deems environmental standards to be inferior in many respects to market-based instruments such as taxes and tradable permits.

Here we restrict our focus to technology standards and their possible role in fostering the transition to a socially preferable technological paradigm. In this perspective, Popp et al. [63] note that the "Incentives to adopt end-of-pipe technologies that only serve to reduce emissions must come from environmental regulation. Therefore, it is not surprising that studies addressing adoption of environmental technologies find that regulations dominate all other firm-specific factors". In terms of the policy under scrutiny, if the policy objective is the widespread adoption of a particular technological solution, then it makes sense to prescribe it in terms of specific technological standards. In the OECD countries, the adoption of end-of pipe techniques is fostered by environmental regulation $[66,90]$. However if the real target of the policy is a more generic environmental endpoint, it would be more effective to specify a set of market-based instruments in terms of that endpoint (e.g., tax per unit of pollution emission) rather than mandating a specific technology. In the case of the policy under scrutiny it is the first order of motives that seem to prevail, at least when the aim is to improve modularity to increase the reparability and reuse of components, and when the idea is to use other materials instead of metals when appropriate.

As noted in [57], "The idea of product standards with an explicit environmental purpose might be more easily accepted if such standards are part of a dynamic policy package that begins with the establishment of EU strategies for dematerialization. Increased R\&D on recycling and material efficiency and the establishment of discussion fora might allow for more ambitious product standards, which would make this instrument more effective."

Beside this need for coordination within a broader environmental policy reform, we notice that product standards feature the usual feasibility characteristics of all command-and-control instruments: they are quite simple to design, but require higher monitoring and enforcement effort by the public administration than market-based instruments to ensure compliance. In the case of technological standards, this concern is somewhat eased by, for instance, making the certification of compliance with the standard compulsory in order to access the market for final products. Some residual leeway for non-compliance would remain for exports to non-EU countries in the quite likely case that a global agreement on the standard is not reached, and to a lesser extent, in the case of illegal commercial exchanges of sub-standard products.

Popp et al. [66] point to a concern raised by the empirical literature about different regulatory treatment of existing producers and new ones. It turns out that command-and-control regulation often imposes stricter standards to newcomers than to incumbents, and such a dual system may worsen the overall environmental impact by unnaturally prolonging the life of dirtier production processes. Thus, while it is probably administratively easier to phase-in new regulations by targeting newcomers first, it is crucial that the same level of stringency is quickly spread to the whole sector targeted by the policy. In this perspective, it is quite likely that unless adequate steps are taken, Member States would adopt such measures with different timings and implementation rules. Strict coordination across the EU invoked by the policy description is indeed very important to achieving the desired results.

\subsection{Overall Assessment}

This subsection illustrates the results of the overall assessment of the policy mix presented in Section 4. It is based on a combined analysis of the possible effects of the four instruments together, and it highlights some major relationships among the four attributes of analysis.

This assessment exercise complements the results of the existing literature on dematerialization policies. Up to now, this literature is still scarce and divided regarding the economic effects of these types of policies. This means that it is not possible to exclude the case of negative effects on the economy-negative results of material taxation are provided by [21]. Moreover, for this policy mix — and for any other measure aiming at reducing virgin material consumption in the EU—the 
evaluation of effectiveness faces a major issue, which relates to the fact that the quantitative relationship between the EU and the world resource consumption has not been quantified yet. Without this type of information, the effects of a reduction in the EU resource consumption on global extraction and refinement externalities as well as on global extraction trends are unknown. Under these circumstances, communicating the introduction of any dematerialization policy to the general public and gaining support for it is undoubtedly a challenging task.

Another point regarding the effectiveness of the policy mix relates to the fact that the EU internal consumption of refined materials is only a fraction of EU total material consumption. This is indeed a consequence of the massive delocalization process of the recent years. This might suggest improving the policy mix effectiveness by modifying the GTR in order to consider taxation of intermediates or final products. In the case of intermediates the issue of double taxation immediately arises, with negative consequences on efficiency. Taxation of final products, in turn, would present the efficiency issues (discussed above in this section), which stem from the incapability of this type of taxation to adequately distinguish between more and less resource efficient processes both at the production and at the disposal level. In principle, the same product may be (partly) recycled, landfilled or incinerated, and these options obviously entail different levels of disposal externalities.

A third point regarding effectiveness relates to the gap between short and long run effects of the policy. While we can expect that in the long run enhanced R\&D activities and the skill enhancement programmes really drive firms towards higher material efficiency, in the short run there is a risk that firms react either by relocating or outsourcing the material intensive production stages, or that they even shut down. The option of protecting these firms through corresponding trade measures is obviously prevented by the current world trade order, as illustrated in many undergraduate trade policy textbooks (e.g., [91]). Alternatively, revenues from environmental taxation could be used to reduce firms' social contributions on labour. This would mitigate the impacts of the environmental taxation; however it would also cancel the opportunities offered by the subsidy on R\&D. In times of fiscal prudence, financing a subsidy of this type may not be immediately feasible.

The policy mix presented in this paper can be considered as an example of a concrete initiative, which the EU could ideally undertake. The results of this qualitative assessment seem to unveil a fundamental issue, which relates to the appropriate choice of the focus for the policy mix: The ultimate sources of concern regarding materials use are externalities and resource limitedness. In this perspective, these should be the policy target, rather than general dematerialization. Dematerialization is not important per se. It is important because it means lower externalities, but if these are the foe to fight, then policies should have them in their core. Extraction and refinement externalities should be reduced throughout the world while dematerialization remains the general framework for action. Very likely, dematerialization would occur but per se this is irrelevant. In other words, policies' focus should shift from the use of virgin materials (and natural resources in general) to the activities performed for their production and refinement.

This shift is not easy to put into practice, however, and a detailed analysis of this alternative strategy goes beyond the scope of this paper. Here we only highlight some major issues, which may arise in its implementation. Domestic extraction activities in the EU are less than ten percent of total world amount [33]. Taxing these activities would very likely create competitiveness issues for the EU extracting firms while leaving untouched most of the extraction activities around the world. An effective reduction of world extraction externalities would require a global initiative, which faces however two major challenges. One comes from those countries (like for example China or India), which are net resource exporter and which may simply disagree with policies affecting their own extraction activities. The other comes from the possibility of free-riding behaviour among countries, which is indeed very probable considering the high dispersion of extraction activities throughout the world (see Section 2). 


\section{Conclusions}

This paper is concerned with dematerialization policies. Its main objective is a qualitative assessment of a policy mix, which aims at fostering the socially efficient use of virgin materials at firm level. These policies owe their design to the research work performed within the DYNAMIX Project. The focus of the paper is much narrower than the one of the DYNAMIX project (from which our analysis originates), as the only type of resources considered are virgin materials (wood, metals and non-metallic minerals) and the policy initiative targets uniquely firms while neglecting, for example, private consumption or disposal activities.

From a methodological point of view, this paper intentionally refrains from providing precise quantifications of the magnitudes and the costs and benefits of policies, which are instead only qualitatively assessed. This is customary for this type of analysis, and it contributes to distinguish it from quantitative studies, which indeed need and employ numbers to quantify the effects of a given policy. It is important to recognize that figures regarding policies (like, for example material taxes) are often either unknown or contentious. Ideally, they should differ among different material types and (within the same type of resource) they should reflect the level of pollution caused by the precise extraction and refinement process. Quantitative studies, which are based on these figures, counterbalance the uncertainty around their entity by producing a high number of comparable simulations, which help to capture the likely quantitative effects of a given policy. However, any policy exhibits a number of aspects, which cannot be quantitatively evaluated because of their unquantifiable nature. The non-quantifiable nature of these aspects does not imply they are less important. On the contrary, they have a prominent role in shaping the feasibility of a policy. As shown in this paper, some of them are typically related to the intrinsic human dimension of any policy, and include, for example institutional, social and even cultural factors. Others are due to the technical difficulties in classifying and measuring the reality on which the policy is to intervene. The existence of these non-quantifiable aspects suggests that its quantitative assessment is only partially possible, and it motivates the qualitative analysis of this paper.

The overall evaluation of the policy mix carried out in this paper is based on the separate assessment of the four main dimensions in economic policy analysis (effectiveness, efficiency, equity, and feasibility). In this framework, the analysis takes an open-economy perspective, which allows accounting for the deep integration of the EU in the world economy and for the role of other countries in global resource consumption.

This aspect is very important for policy effectiveness. In the area of dematerialization, quantitative studies are still too scarce and divided to allow any significant conclusion. A major concern relates the effects that unilateral EU material policies can plausibly have on global extraction and disposal externalities. This concern is motivated by the apparent lack of reliable figures regarding the relationship between the EU and the global resource consumption. To our knowledge, the effect of a unilateral EU dematerialization policy on global extraction has not been calculated yet. This is of course a crucial issue for political feasibility as well, because we cannot exclude negative economic effects of dematerialization policies. A last point hitting effectiveness of material policies at the first-industrial-use level comes from the opportunities offered to firms by offshoring and outsourcing material-intensive production stages, with the advantage of escaping costly domestic material policies.

The paper shares the view that virgin material (resource) consumption is responsible for most externalities, and it raises serious concerns regarding the limitedness issue. However, building on the policy evaluation, it shows that initiatives, which set dematerialization as their main (only) objective, may prove economically inefficient. These types of initiatives, which target material throughputs instead of externalities, miss the opportunities offered by direct interventions at the point where externalities arise, i.e., at the extraction and at the refinement stage. A material tax has to be material-specific, but this is not sufficient. Within the same material type, it is necessary to distinguish between units extracted through environmentally friendly or unfriendly processes. While our analysis confirms that dematerialization is a prominent objective to pursue, it shows that 
the efficient reduction in material consumption cannot be pursued through measures, which target used quantities. Quite differently, policy intervention should focus on processes as these naturally differ from one another, and they are responsible for different environmental impacts. As these types of policies in any case raise material prices, this strategy will ultimately lead to (hopefully efficient) dematerialization.

Acknowledgments: The research leading to the presented findings has received funding from the European Union's Seventh Framework Programme for research, technological development and demonstration under grant agreement No. 308674, DYNAMIX project. The authors are grateful for their precious comments and suggestions to two anonymous referees, the Editor and the external Editor of this issue of this Journal, and to Martin Hirschnitz-Garbers, Martin Nesbit and Barbara Racah.

Author Contributions: Andrea Bigano contributed to the main research and writing on Sections 3-5; Aleksander Śniegocki did the main research and contributed to writing Section 2; Jacopo Zotti did the main research and writing on Sections 1, 2 and 4-6.

Conflicts of Interest: The authors declare no conflicts of interest.

\section{References}

1. Krausmann, F.; Gingrich, S.; Eisenmenger, N.; Erb, K.-H.; Haberl, H.; Fischer-Kowalski, M. Growth in global materials use, GDP and population during the 20th Century. Ecol. Econ. 2009, 68, 2696-2705. [CrossRef]

2. Global Material Flows Database. Available online: http://www.materialflows.net/home/ (accessed on 5 May 2016).

3. Lomborg, B. The Skeptical Environmentalist: Measuring the Real State of the World; Cambridge University Press: Cambridge, UK, 2001.

4. Lomborg, B. Global Crises, Global Solutions; Cambridge University Press: Cambridge, UK, 2004.

5. Simon, J. Resources, population, environment: An oversupply of false bad news. Science 1980, 208, 1431-1437. [CrossRef] [PubMed]

6. Simon, J. The Ultimate Resource; Princeton University Press: Princeton, NJ, USA, 1981.

7. Ayres, R.U. Sustainability economics: Where do we stand? Ecol. Econ. 2008, 67, 281-310. [CrossRef]

8. Bowen, A.; Hepburn, C. Green growth: An assessment. Oxf. Rev. Econ. Policy 2014, 30, 407-422. [CrossRef]

9. Ayres, R.U.; Kneese, A.V. Production, consumption and externalities. Am. Econ. Rev. 1969, 59, 282-297.

10. European Commission. Roadmap to a Resource Efficient Europe, Communication from the Commission to the European Parliament, the Council, the European Economic and Social Committee and the Committee of the Regions; Roadmap to a Resource Efficient Europe. COM (2011) 571; European Commission: Brussels, Belgium, 2011.

11. European Commission. Thematic Strategy on the Sustainable Use of Natural Resources; European Commission: Brussels, Belgium, 2005.

12. Bemardini, O.; Calli, R. Dematerialization: Long term trends in the intensity of use of materials and energy. Futures 1993, 25, 431-448. [CrossRef]

13. Smulders, S. Environmental policy and sustainable economic growth. An endogenous growth perspective. Economist 1995, 143, 163-195. [CrossRef]

14. Smulders, S. Endogenous growth theory and the environment. In Handbook of Environmental and Resource Economics; van den Bergh, J.C.J.M., Ed.; Edward Elgar: Cheltenham, UK, 1999.

15. Lucas, R.E. On the mechanics of economic development. J. Monet. Econ. 1998, 22, 3-42. [CrossRef]

16. Ayres, R.U.; van den Bergh, J.C.J.M. A theory of economic growth with material/energy resources and dematerialization: Interaction of three growth mechanisms. Ecol. Econ. 2005, 55, 96-118. [CrossRef]

17. Warr, B.; Ayres, R.U. Useful work and information as drivers of economic growth. Ecol. Econ. 2012, 73, 93-102. [CrossRef]

18. Georgescu-Roegen, N. The Entropy Law and the Economic Process; Harvard University Press: Cambridge, MA, USA, 1971.

19. Daly, H.E. Entropy, growth and the political economy. In Scarcity and Growth Reconsidered; Smith, V.K., Ed.; Johns Hopkins University Press: Baltimore, MD, USA, 1979.

20. Stern, D.I. The rise and fall of the environmental Kuznets curve. World Dev. 2004, 32, 1419-1439. [CrossRef]

21. Dellink, R.B.; Kandelaars, P.P.A.A.H. An empirical analysis of dematerialisation: Application to metal policies in The Netherlands. Ecol. Econ. 2000, 33, 205-218. [CrossRef] 
22. European Commission. Study on Modelling of the Economic and Environmental Impacts of Raw Material Consumption; European Commission: Brussels, Belgium, 2014.

23. Quah, D. The Weightless Economy in Economic Development; London School of Economics and Political Science: London, UK, 1999.

24. Coyle, D. The Weightless World: Strategies for Managing the Digital Economy; MIT Press: Cambridge, MA, USA, 1998.

25. Hepburn, C.J.; Bowen, A. Prosperity with growth: Economic growth, climate change and environmental limits. In Handbook of Energy and Climate Change; Fouquet, R., Ed.; Edward Elgar: Cheltenham, UK, 2013.

26. Pearce, D.; Turner, R.K. Economics of Natural Resources and the Environment; Harvester Wheatsheaf: London, UK, 1990.

27. Turner, R.K.; Salmons, R.; Powell, J.; Craighill, A. Green taxes, waste management and political economy. J. Environ. Manag. 1998, 53, 121-136. [CrossRef]

28. Bosquet, B. Environmental tax reform: Does it work? A survey of the empirical evidence. Ecol. Econ. 2000, 34, 19-32. [CrossRef]

29. Chang, C.P.; Berdiev, A.N. The political economy of energy regulation in OECD countries. Energy Econ. 2011, 33, 816-825. [CrossRef]

30. OECD. Material Resources, Productivity and the Environment, OECD Green Growth Studies; OECD: Paris, France, 2015.

31. De Serres, A.; Murtin, F.; Nicoletti, G. A Framework for Assessing Green Growth Policies; OECD: Paris, France, 2010.

32. Lehmann, P.; Gawel, E. Why should support schemes for renewable electricity complement the EU emissions trading scheme? Energy Policy 2013, 52, 597-607. [CrossRef]

33. Wiedmann, T.O.; Schandlb, H.; Lenzenc, M.; Moranc, D.; Suhf, S.; West, J.; Kanemoto, K. The material footprint of nations. Proc. Natl. Acad. Sci. USA 2015, 112, 6271-6276. [CrossRef] [PubMed]

34. Tukker, A.; de Koning, A.; Wood, R.; Hawkins, T.; Lutter, S.; Acosta, J.; Cantuche, J.M.R.; Bouwmeester, M.; Oosterhaven, J.; Drosdowski, T.; et al. EXIOPOL—Development and illustrative analyses of a detailed global MR EE SUT/IOT. Econ. Syst. Res. 2013, 25, 50-70. [CrossRef]

35. Bruckner, M.; Giljum, S.; Lutz, C.; Wiebe, K.S. Materials embodied in international trade—Global material extraction and consumption between 1995 and 2005. Glob. Environ. Chang. 2012, 22, 568-576. [CrossRef]

36. Wiebe, K.S.; Bruckner, M.; Giljum, S.; Lutz, C.; Polzin, C. Carbon and materials embodied in the international trade of emerging economies. J. Ind. Ecol. 2012, 16, 636-646. [CrossRef]

37. Resnick, D.; Tarp, F.; Thurlow, J. The political economy of green growth: Cases from Southern Africa. Public Adm. Dev. 2012, 32, 215-228. [CrossRef]

38. Umpfenbach, K. Common Approach for DYNAMIX. Deliverable 1.2 of DYNAMIX; Ecologic Institute: Berlin, Germany, 2013.

39. European Commission. Towards a Circular Economy: A Zero Waste Programme for Europe, Communication from the Commission to the European Parliament, the Council, the European Economic and Social Committee and the Committee of the Regions; COM (2014) 0398 Final/2; European Commission: Brussels, Belgium, 2014.

40. EASAC. Circular Economy: A Commentary from the Perspectives of the Natural and Social Sciences; European Academies' Science Advisory Council: Halle, Germany, 2015.

41. Happaerts, S. International Discourses and Practices of Sustainable Materials Management; Policy Research Centre on Sustainable Materials Management: Leuven, Belgium, 2014.

42. Lopes, A.F.; Bego, K. DYNAMIX Policy Mix Evaluation. A Sound Material Cycle Society in Japan. Case Study of DYNAMIX; IEEP: Stevenage, UK, 2013. Available online: http:/ /dynamix-project.eu/sites/default/files / Materials\%20and\%20metals_Japan.pdf (accessed on 4 February 2016).

43. Bahn-Walkowiak, B.; Steger, S. Resource targets in Europe and worldwide: An overview. Resources 2015, 4, 597-620. [CrossRef]

44. Fritsche, U.R.; Gavilan, I.; Leagnavar, P. Elaborating the International Discussion on Resource Efficiency (ENTIRE): Part I: Resource Efficiency Policies in Various Countries Annex Report; IINAS: Darmstadt, Germany, 2013.

45. EPA, United States Environmental Protection Agency. Sustainable Materials Management. Available online: http:/ / www.epa.gov/smm (accessed on 4 February 2016).

46. West, J.; Schandl, H.; Heyenga, S.; Chen, S. Resource Efficiency: Economics and Outlook for China; UNEP: Bangkok, Thailand, 2013. 
47. Su, B.; Heshmati, A.; Geng, Y.; Yu, X. A review of the circular economy in China: Moving from rhetoric to implementation. J. Clean. Prod. 2013, 42, 215-227. [CrossRef]

48. Wu, H.Q.; Shi, Y.; Xia, Q.; Zhu, W.D. Effectiveness of the policy of circular economy in China: A DEA-based analysis for the period of 11th Five-Year-Plan. Resour. Conserv. Recycl. 2014, 83, 163-175. [CrossRef]

49. Rossell, C. Using multiple criteria to evaluate public policies. The case of school desegregation. Am. Politics Res. 1993, 21, 155-184. [CrossRef]

50. OECD. Consumption Tax Trends; OECD: Paris, France, 1999.

51. Clinch, J.P.; Dunnea, L.; Dresner, S. Environmental and wider implications of political impediments to environmental tax reform. Energy Policy 2006, 34, 960-970. [CrossRef]

52. Caraher, M.; Cowburnb, G. Guest Commentary: Fat and other taxes, lessons for the implementation of preventive policies. Prev. Med. 2015, 77, 204-206. [CrossRef] [PubMed]

53. A Panorama on Energy Taxes and Green Tax Reforms. Available online: https://www.google.com/ url?sa=t\&rct=j\&q=\&esrc=s\&source=web\&cd=1\&cad=rja\&uact=8\&ved=0ahUKEwilueG2sobOAhUBk5QKH VTSBw8QFggeMAA\&url=http $\% 3 \mathrm{~A} \% 2 \mathrm{~F} \% 2$ Feforenergy.org\%2Fdocpublicaciones $\% 2 F d o c u m e n t o s-d e-t r a b a j o$ \%2FWP08-2013.pdf\&usg=AFQjCNHpo8TyJ_hGAqKdbRJJRWW8uE3yvA (accessed on 18 August 2015).

54. Social and Political Responses to Ecological Tax Reform in Europe. Available online: http://www.sciencedirect. com/science/journal/03014215/34/8 (accessed on 22 July 2016).

55. Bødker, M.; Pisingera, C.; Tofta, U.; Jørgensena, T. The rise and fall of the world's first fat tax. Health Policy 2015, 119, 737-742. [CrossRef] [PubMed]

56. Eckermann, F.; Golde, M.; Herczeg, M.; Mazzanti, M.; Montini, A.; Zoboli, R. Resource Taxation and Resource Efficiency along the Value Chain of Mineral Resources; European Topic Centre on Sustainable Consumption and Production: Copenhagen, Danmark, 2012.

57. Development of DYNAMIX Policy Mixes. Available online: http://dynamix-project.eu/developmentdynamix-policy-mixes (accessed on 26 October 2015).

58. McCleary, W. The earmarking of government revenue: A review of some World Bank experience. World Bank Res. Obs. 1991, 2, 81-104. [CrossRef]

59. Carbon Pricing: How Best to Use the Revenue? Available online: http://www.lse.ac.uk/GranthamInstitute/ wp-content/uploads/2015/11/Bowen-policy-brief-2015.pdf (accessed on 15 April 2016).

60. Weitzman, M.L. Prices vs. quantities. Rev. Econ. Stud. 1978, 41, 477-491. [CrossRef]

61. Jaffe, A.B.; Newell, R.G.; Stavins, R.N. A tale of two market failures: Technology and environmental policy. Ecol. Econ. 2005, 54, 164-174. [CrossRef]

62. Magat, W.A. Pollution control and technological advance: A dynamic model of the firm. J. Environ. Econ. Manag. 1978, 5, 1-25. [CrossRef]

63. Popp, D.; Newell, R.G.; Jaffe, A.B. Energy, the environment, and technological change. Handb. Econ. Innov. J. 2011, 2, 873-937.

64. Albrecht, J. The use of consumption taxes to re-launch green tax reforms. Int. Rev. Law Econ. 2006, 26, 88-103. [CrossRef]

65. Economic Welfare and the Allocation of Resources to Invention. Available online: http://www.nber.org/ chapters/c2144.pdf (accessed on 17 April 2016).

66. A Model for Recycling Target Policy under Imperfect Competition with and without Cooperation between Firms. Available online: http:/ /www.ip.kyusan-u.ac.jp/keizai-kiyo/dp45.pdf (accessed on 30 March 2016).

67. Popp, D. R\&D subsidies and climate policy: Is there a "free lunch". Clim. Chang. 2006, 77, 311-341.

68. Fischer, C.; Newell, R. Environmental and technology policies for climate mitigation. J. Environ. Econ. Manag. 2008, 55, 142-162. [CrossRef]

69. Baylor, M. Ranking Tax Distortions in Dynamic General Equilibrium Models: A Survey; Department of Finance: Sacramento, CA, USA, 2005.

70. European Environmental Agency (EEA). Environmental Tax Reform in Europe: Implications for Income Distribution; European Environmental Agency: Copenhagen, Denmark, 2011.

71. Ekins, P.; Speck, S. Environmental Tax Reform: A Policy for Green Growth; Oxford University Press: Oxford, UK, 2011.

72. Böhringer, C.; Müller, A. Environmental Tax Reforms in Switzerland a Computable General Equilibrium Impact Analysis; IDEAS: Ottawa, ON, Canada, 2014.

73. OECD. Environment and Employment: An Assessment; OECD: Paris, France, 2004. 
74. Agnolucci, P. The effect of the German and UK environmental tax reforms on the demand for labour and energy. In Environmental Tax Reform: A Policy for Green Growth; Ekins, P., Speck, S., Eds.; Oxford University Press: Oxford, UK, 2011.

75. Speck, S.; Summerton, P.; Lee, D.; Wiebe, K. Environmental taxes and ETRs in Europe: Current situation and a review of the modelling literature. In Environmental Tax Reform: A Policy for Green Growth; Ekins, P., Speck, S., Eds.; Oxford University Press: Oxford, UK, 2011.

76. Buchanan, J.M.; Tullock, G. Polluters' profits and political response: Direct controls versus taxes. Am. Econ. Rev. 1975, 65, 139-147.

77. Boyer, M.; Laffont, J.-J. Toward a political theory on the emergence of environmental incentive regulation. Rand J. Econ. 1999, 30, 137-157. [CrossRef]

78. Aidt, T.S.; Dutta, J. Transitional politics: Emerging incentive-based instruments in environmental regulation. J. Environ. Econ. Manag. 2004, 47, 458-479. [CrossRef]

79. Oates, W.E.; Portney, P.R. The political economy of environmental policy. In Handbook of Environmental Economics; Mäler, K.-G., Vincent, J.R., Eds.; Elsevier: Amsterdam, The Netherlands, 2003; Volume 1, pp. 325-354.

80. Karplus, V.J. The Case for a Higher Gasoline Tax. New York Times, 22 February 2013, p. A23.

81. Thøgersen, J. Monetary incentives and environmental concern: Effects of a differentiated garbage fee. J. Consum. Policy 1994, 17, 407-442. [CrossRef]

82. Alesina, A.; Angeletos, G.M. Fairness and redistribution. Am. Econ. Rev. 2005, 95, 960-980. [CrossRef]

83. Mais où Est Donc Passée la Taxe Pique-Nique? Available online: http://www.lexpress.fr/actualite/ environnement/mais-ou-est-doncpassee-la-taxe-pique-nique_1184651.html\#wrkThVQbxZKbjhTL.99 (accessed on 13 May 2016). (In French)

84. Dresner, S.; Dunne, L.; Clinch, P.; Beuermann, C. Social and political responses to ecological tax reform in Europe: An introduction to the special issue. Energy Policy 2006, 34, 895-904. [CrossRef]

85. Johansson, N.; Krook, J.; Eklund, M. Institutional conditions for Swedish metal production: A comparison of subsidies to metal mining and metal recycling. Resour. Policy 2014, 41, 72-82. [CrossRef]

86. Withana, S.; ten Brink, P.; Illes, A.; Nanni, S.; Watkins, E. Environmental Tax Reform in Europe: Opportunities for the Future; IEEP: Brussels, Belgium, 5 June 2014.

87. Study on Assessing the Environmental Fiscal Reform Potential for the EU28. Available online: http:/ /ec.europa.eu/environment/integration/green_semester/pdf/Eunomia\%20EFR\%20Final\%20Report\% 20MAIN\%20REPORT.pdf (accessed on 30 April 2016).

88. Cedefop; OECD. Green Skills and Innovation for Inclusive Growth; Publications Office of the European Union: Luxembourg City, Luxembourg, 2015.

89. Ecorys. Programmes to Promote Environmental Skills; Ecorys, EC: Rotterdam, The Netherlands, 2010.

90. Frondel, M.; Horbach, J.; Rennings, K. End-of-pipe or cleaner production? An empirical comparison of environmental innovation decisions across OECD countries. Bus. Strategy Environ. 2007, 16, 571-584. [CrossRef]

91. Krugman, P.R.; Obstfeld, M.; Melitz, M. International Economics: Theory and Policy, 10th ed.; Pearson: Upper Saddle River, NJ, USA, 2014.

(C) 2016 by the authors; licensee MDPI, Basel, Switzerland. This article is an open access article distributed under the terms and conditions of the Creative Commons Attribution (CC-BY) license (http://creativecommons.org/licenses/by/4.0/). 